\title{
IS ENGLISH AS A MEDIUM OF INSTRUCTION PROBLEM FOR UNDERGRADUATE MEDICAL STUDENTS ?
}

\author{
Hossain $\mathrm{S}^{1}$, Shamim $\mathrm{KM}^{2}$, Shahana $\mathrm{N}^{3}$, Habib $\mathrm{MA}^{4}$, Rahman $\mathrm{A}^{5}$
}

\begin{abstract}
Introduction: The students of a country like Bangladesh, where language of medical education is completely English, suffer from a lot of problems in grasping English and also Latin and Greek terms used in English.

Objective: This study was aimed to estimate the extents and to identify the nature of the problems faced by the undergraduate students in different aspects of English used in Anatomy.

Methods: The study was conducted on 191 third year medical students, who had just passed the Anatomy portion of their undergraduate course from two renowned government medical colleges and one private medical college of Bangladesh. A written assessment test of students' performance was designed using two sets of questions as the instrument of the test. Each student was graded, according to the percentage frequency of correct responses, as having Grade IV difficulty (up to $20 \%$ ), Grade III difficulty $\mathbf{2 0 . 0 1 \%}$ to $\mathbf{4 0 \%})$, Grade II difficulty $(\mathbf{4 0 . 0 1 \%}$ to $60 \%)$, Grade I difficulty $(60.01 \%$ to $80 \%)$ and Grade 0 with 'no difficulty' (above $80.01 \%$ ). Comments were also collected from the students regarding their problems with English used in Anatomy.

Results: An average of only about $48.2 \%$ responses on 'English used in Anatomy' was correct, ranging from about 20 to $\mathbf{7 0 \%}$. An arbitrary grading of difficulty level showed that $\mathbf{7 5 \%}$ of the students were suffering from Grade II to Grade III difficulties. Performance of the students showed that the undergraduate medical students of Bangladesh were facing varying but noticeable amounts of difficulty with most of the areas of 'English used in Anatomy'.

Conclusion: Organized, regular ways of dealing with these problems should be devised taking into consideration the specific aspects showing weakness and based on principles of terminology and English rather than on individual terms or words.
\end{abstract}

Key word: English used in Anatomy, difficulty, undergraduate medical student

\section{Introduction}

Now-a-days, medical education necessitates the cross- fertilization of medical ideas and thus realises the need of monolingualism. So, the multicultural and multilingual world now forwards to get a standardised language as the medium of medical education. Mather also expressed the same view: "The standard languages now used in medical schools undoubtedly provide an important and essential medium of education"1. There are countries not having English as their first language, but employ English as the medium of medical education. Mather observed that in many countries, standard languages have become the lingua franca while that may not be the national language. He mentioned the name of Saudi Arabia or Kuwait; but similar is the situation for Bangladesh as well. In his view, however, internal bilingualism is enshrined in medical school policy of such countries. In Bangladesh, English is also the official language of medical education, but the unofficial presence of Bengali among the students and teachers should be mentioned ${ }^{1}$.

Most of the Bengali-speaking students studying in the medical colleges come from Bengali medium institutions. So, the abrupt change of medium of language becomes a potential barrier to academic success. Ypinazar and Margolis while discussing about the cultural and linguistic boundaries of the junior (first year) medical students of Arabian gulf, observed that, social anthropology has demonstrated that there is a strategic mixing of language with culture and that both culture and social systems are conceptualised in language and this would suggest that students learning medicine in English, their second language, could experience dissonance between the contents of their courses and context of their everyday lives ${ }^{2}$. "Lack of a minimum level of competence in English seriously jeopardises the ability of students to listen to, participate in and understand classes, to read textbooks, to sit for written, oral or practical examination and prepare assignments" commented Hayes et al about the non-English speaking background (NESB) pre-clinical medical students of Australia ${ }^{3}$. They investigated and found that students' entrance levels in English correlated well with their final examination results and the quality and quantity of their English also correlated highly with scores in class tests.

1. Maj Sharmin Hossain MBBS, M Phil, Asstt Prof, Dept of Anatomy, AFMC; 2. Prof Khondker Manzare Shamim MBBS, M Phil, PhD, Prof and Head, Dept of Anatomy, BSMMU; 3. Nahida Shahana MSc, M Phil, Bangladesh Medical College, Dhaka; 4. Col Md Ahsan Habib MBBS, M Phil, Professor and Head, Dept of Anatomy, AFMC; 5. Lt Col Md Azizur Rahman MBBS, M Phil, Assoc Prof, Dept of Anatomy, AFMC. 
Anatomy being the beginner and basic subject, offers a great thrust to new comer Bengali-based students with a great volume of English as well as Latin anatomical terminology. To cope up with this vast amount of terminologies from textbooks written by English speaking background (ESB) writers becomes a challenge to any medical student and a tendency of memorizing upper hands. Poor written proficiency, as defined by accuracy and clarity, may be as much a function of inadequate student education in the medical curriculum as a reflection of difficulties with English language proficiency-was also the consideration of Hansen \& Robert who are working with the language proficiency of NESB undergraduate students of a university of South Australia $^{4}$

This study aimed at addressing some of the problem areas faced by undergraduate medical students of Bangladesh regarding 'English used in Anatomy'.

\section{Materials and Methods}

Selection of subjects (students). For this performancebased study, 191 third year undergraduate students of three medical colleges, who had just passed the 1 st professional examination, were selected. Of the medical colleges, two were government and one was private. Maintenance of anonymity was a demand of the medical colleges before allowing the researcher to take the test. The cause behind the selection of students was that they had covered the whole syllabus of Anatomy in recent time. Foreign students were excluded from the study.

Instrument for the test. For testing the students, two sets of questions were prepared as the instrument of the test. In constructing questions on the issue 'proficiency of English used in Anatomy', the aspects of English assessed by Holbrook and Bourke and Cobbin et al in their 'English Skill Assessment (ESA) test' were followed in the present study ${ }^{5,6}$. Following operational terminologies were used :

Reading skill - English that is required to understand the anatomical texts.

Listening skill - English that is required to follow teaching in the classes

Writing skill - English that is required to write in exams or in classes and to produce practical documents and other written assignments.

Area - Various aspects of English to be tested for proficiency

OItem - Sub-heads of an 'area'. One or more questions were prepared for each item.

Following factors were considered while constructing the instrument of the test:

Using personal and peer experiences

- Selection and examination of answer scripts of undergraduate Anatomy

- $\mathbb{S}$ creening of different Anatomy textbooks
WConsultation of English grammar books

$\square$ Consultation of available test documents and other textual resources related to English language proficiency tests

Questions were prepared to carry out a 60 minute-long students' performance-based study to assess their understanding of English used in Anatomy. Every alternate student was given with one set of question, so that two students sitting side by side got two separate sets. Of them 95 students answered the Set A questions and 96 students answered the Set B questions. Number of responses tested for a particular item in each set of question was variable.

Types of question used. The questions included in the two sets were close-ended and called for different types of response: Multiple Choice Question (MCQ) type responses (multiple true-false type, one best response type etc.), Short Answer Question (SAQ) type responses (filling in the blanks, writing in one or two words, translating short or long sentences, changing the voice, rephrasing a sentence, rewriting a sentence with correct words for spelling, tense etc). Questions were asked in Bengali keeping all the technical terms in English, so that inability to understand the language due to a lower English proficiency would not affect the students' understanding of the questions and thereby obscure the real picture of their performance in the test.

Testing students' performance. An arbitrary grading scale was used to categorise the level of difficulties the students had with 'English used in Anatomy' (as evidenced through their performance):

- Grade 0 (No difficulty) $=80.01 \%$ and above correct responses

- Grade I difficulty $=60.01 \%-80 \%$ correct responses

- Grade II difficulty $=40.01 \%-60 \%$ correct responses

- Grade III difficulty $=20.01 \%$ - $40 \%$ correct responses

- Grade IV difficulty $=$ up to $20 \%$ correct responses

\section{Results}

In the present study, 191 third year (MBBS) students who had recently passed the Anatomy part of the course took part in a written assessment session by answering one of two supplied sets of questions. The frequencies of correct responses were expressed as proportions of correct responses from the students out of the highest possible correct responses regarding individual item. Table-I shows the frequencies of correct responses from the students on different items of different areas of 'English used in Anatomy'.

The overall proportions of correct and incorrect responses of the students are compared in Fig-1. It was evident from the results tables that in case of many of the 'items' of English, the frequency of correct responses was marked less than $50 \%$. However, in the area 'understanding the meaning of prefix/suffix' the 
Table-I: Frequencies of correct responses from students in different areas of English used in Anatomy.

\begin{tabular}{|c|c|c|c|c|}
\hline Area & Items & Examples & $\begin{array}{c}\star \text { Number of } \\
\text { responses }\end{array}$ & $\begin{array}{l}\text { \%Frequency of } \\
\text { correct responses }\end{array}$ \\
\hline \multirow{3}{*}{$\begin{array}{l}\text { Reading } \\
\text { comprehension }\end{array}$} & $\begin{array}{l}\text { a) Understanding main } \\
\text { ideas }\end{array}$ & \multirow{3}{*}{$\begin{array}{l}\text { One paragraph was } \\
\text { given in each set of } \\
\text { questions from a } \\
\text { textbook }\end{array}$} & 2 & $24.6 \%$ of 191 \\
\hline & $\begin{array}{l}\text { b) Understanding direct } \\
\text { statements }\end{array}$ & & 3 & $61.8 \%$ of 286 \\
\hline & c) Drawing inferences & & 2 & $30.8 \%$ of 191 \\
\hline \multirow[t]{5}{*}{ Vocabulary } & a) Identifying a synonym & $\begin{array}{l}\text { Manifestation/ } \\
\text { constriction }\end{array}$ & 10 & $27.6 \%$ of 955 \\
\hline & $\begin{array}{l}\text { b) Understanding the use } \\
\text { of prefix \& suffix }\end{array}$ & & & \\
\hline & $\begin{array}{l}\text { i) Identifying a } \\
\text { prefix/suffix }\end{array}$ & Aphasia/sesamoid & 5 & $60.4 \%$ of 475 \\
\hline & $\begin{array}{l}\text { ii) Understanding the } \\
\text { meaning of a prefix }\end{array}$ & Polymastia & 13 & $72.7 \%$ of 1243 \\
\hline & $\begin{array}{l}\text { iii) Making a new word } \\
\text { with the prefix }\end{array}$ & Ante/anti & 6 & $59 \%$ of 576 \\
\hline \multirow[t]{4}{*}{ Spelling } & $\begin{array}{l}\text { a) Applying the knowledge } \\
\text { of British/American style } \\
\text { of spelling }\end{array}$ & Amenorrhoea/ fiber & 5 & $33.6 \%$ of 475 \\
\hline & $\begin{array}{l}\text { b) Applying the knowledge } \\
\text { of homophones in spelling }\end{array}$ & $\begin{array}{l}\text { Label/ level } \\
\text { Matter/mater }\end{array}$ & 4 & $51 \%$ of 382 \\
\hline & $\begin{array}{l}\text { c) Applying the knowledge } \\
\text { of silent 'e' in spelling }\end{array}$ & Secret/ secrete & 1 & $36.8 \%$ of 95 \\
\hline & $\begin{array}{l}\text { d) Applying the knowledge } \\
\text { of other phenomena in } \\
\text { spelling }\end{array}$ & Mucous /mucus & 2 & $58.4 \%$ of 190 \\
\hline \multirow[t]{5}{*}{ Other areas } & $\begin{array}{l}\text { a) Using appropriate } \\
\text { preposition }\end{array}$ & $\begin{array}{l}\text { Divides into/ } \\
\text { Runs through }\end{array}$ & 6 & $57.3 \%$ of 570 \\
\hline & b) Changing voice & $\begin{array}{l}\text { The trunk of right } \\
\text { coronary artery } \\
\text { changes course three } \\
\text { times }\end{array}$ & 4 & $40.3 \%$ of 382 \\
\hline & $\begin{array}{l}\text { c) Translating from } \\
\text { Bengali to English }\end{array}$ & $\begin{array}{l}\text { Something above the } \\
\text { nucleus/anything } \\
\text { surrounding the orbit }\end{array}$ & 6 & $61.4 \%$ of 573 \\
\hline & d) Understanding phrase & ‘Apart from’ means & 6 & $51.3 \%$ of 573 \\
\hline & e) Changing the verb form & $\begin{array}{l}\text { The collagen fibers } \\
\text { (appear) white when } \\
\text { they are present in } \\
\text { great number }\end{array}$ & 6 & $44.6 \%$ of 573 \\
\hline
\end{tabular}

percentage frequency of correct responses was above $70 \%$. This high frequency must have affected the overall frequency. When the levels of performance of individual students were considered, it was found that most $(75 \%)$ of the students were suffering from Grade II to Grade III difficulties (Fig-2). 


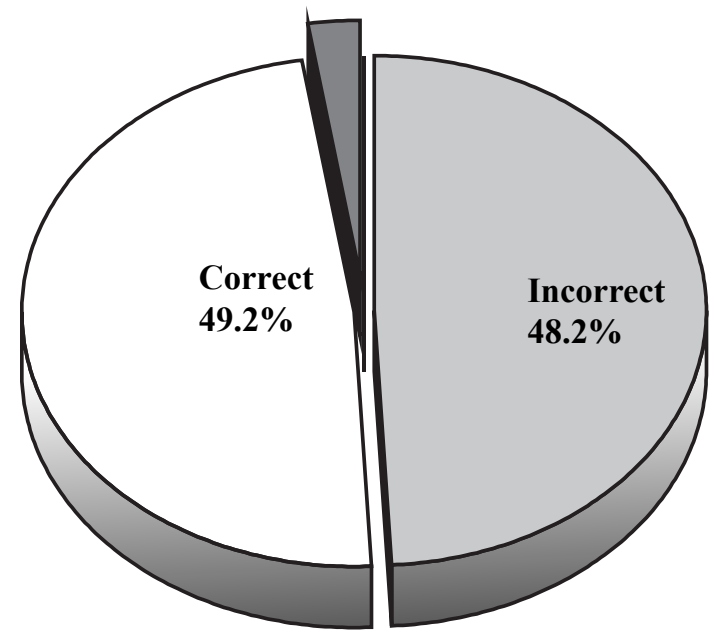

Fig-1: Percentage frequencies of correct and incorrect responses from students regarding questions on English language.

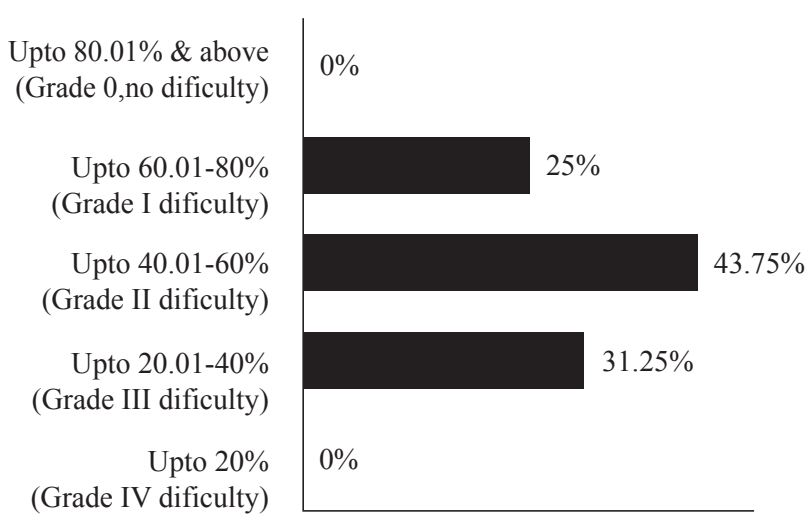

$0 \% \quad 10 \% \quad 20 \% \quad 30 \% \quad 40 \% \quad 50 \%$

Fig-2: Percentage of frequencies of correct responses as per grading scale to categorize the level of difficulties of individual student on different areas of 'English used in Anatomy'.

\section{Discussion}

Flaherty et al note that the physicians need to be able to read with speed and comprehension in order to keep abreast of the plethora of new clinical research as well as with the mundane but voluminous amount of written material appearing before his eyes in the course of everyday clinical practice ${ }^{7}$. They also observed that writing was getting enough importance in medicine nowa-days. However, Yanhoff and Burg maintain that the quality of medical writing has been a long time concern and the negative consequences of ineffective writing by physicians had also been documented; for instance, failure to publish research, loss of grant proposals, increased litigation, and reduced patient compliance ${ }^{8}$. Author also observed that the lack of formal school and textbook instruction in the major types of medical writing points to an important but little explored area for future teaching. It was understandable that most of the Bangladeshi students and doctors are many miles back in this field.
Reading comprehension was a very important concern of this research, because difficulty in understanding the textbooks by reading makes the students more dependent on the so-called 'guidebooks' or 'notebooks'. When the students were asked regarding this, most of them identified this understanding difficulty as the cause of more popularity of Anatomy textbooks written by Bangladeshi and Indian writers. For testing the area of reading one paragraph was given in each set of questions and seven questions were asked on the paragraphs covering three items as used for reading comprehension by Cobbin et $\mathrm{al}^{6}$. Students' performance was relatively better $(>60 \%$ of correct responses) in the item of 'understanding direct statements' in comparison to the other two items, 'understanding main ideas' and 'drawing inferences' ( $<30 \%$ of correct responses). The performance of the students in the area of reading comprehension was variable and, in fact, not satisfactory in the items where more understanding was required. Cobbin et al stated similarly ${ }^{6}$. The students showed relatively better performance in the item where direct statements were expressed as understanding direct statement involves the simplest comprehension skills, according to Cobbin et $\mathrm{al}^{6}$. It should be mentioned, however, that compared to the tests like ESA, both the paragraphs used in the present study were quite short. Letelier et al conducted a comparative study on English and Spanish-speaking physicians. It was observed that in understanding the written English language was a barrier while teaching Evidence-based Health Care (EBHC) to Spanish-speaking physicians ${ }^{9}$.

In most of the items of vocabulary and spelling, correct response rate was below $60 \%$. The students only performed better (about 70\%) in the items of understanding the meaning of prefix and suffix of the area vocabulary. The response in using verb was not satisfactory as also showed by Cobbin et al in his study ${ }^{6}$. Use of verbs in anatomical texts is very extensive and proper understanding of use of verbs is essential for proper understanding of anatomical texts. As undergraduate students are always writing and reading in English, many a time they are changing voice for expressing their understanding. Some questions were set to assess their capabilities of changing voice. Sentence like "The trunk of the right coronary artery changes course three times" was given to change the voice and the $40 \%$ correct response rate in this item is showing the extent of weakness of the students in expressing their knowledge. The other items of this area were also not shown any satisfactory performance of the students.

An arbitrary grading system was developed following those who tested the English language proficiency of their students. Holbrook and Bourke regarded the $70 \%$ correct response rate as a cut-off score ${ }^{5}$. On the other hand, Hansen and Roberts used 19 out of $23(82 \%)$ as cut off 
score for differentiating students between 'with difficulties' and 'without difficulty'4. However, as explained in the methods section that the present study was not intended to make such differentiation. Rather, an arbitrary grading system was developed to grade the students according to their performance in the test carried out. It was expected that the grading system would provide some idea about the English language proficiency of the students. In this grading, the above mentioned $70 \%$ and $82 \%$ cut off marks were considered and the students with $80 \%$ and above correct responses were graded as Grade 0 or No difficulty. The other scores were also graded accordingly. From this study, it was seen that about $75 \%$ of students are suffering from Grade II and Grade III (20.01-60\% of correct responses) difficulty in 'English used in Anatomy' and only 25\% were in 'Grade I'. No student had Grade IV difficulty, but it is very clear that most of the students were suffering from that much difficulty that will jeopardize their understanding textbook and facing written and oral examinations. However, when the students were asked about their own perception of their English language proficiency, 40\% replied that they were quite good or very good in English. Nevertheless, another $40 \%$ were undecided about their proficiency and only $20 \%$ thought themselves as quite bad or very bad in English. So, the result of the performance of the students in the study does not tally with their comments.

This language problem produces a long term effects. Even during practical life practitioners faces problem in communicating patients. A prospective study on this field was conducted on the students of Faculty of Medicine and Health Sciences, United Arab Emirate (UAE) University, which follow a curriculum based on a British medical school model. After extensive communication skills training in English, which included numerous sessions of communication skills training and history taking exclusively in English, only three-quarters of students felt confident in taking a history in English. One-quarter expressed confidence in taking a history in Arabic. This suggests that, it is not easy for an Asian student to convert the communication skills learnt in English into their native language ${ }^{10}$. Anna et al in a study on a small group $(n=18)$ of general practitioner registrars training in South Australia identified that $17 \%$ of them had substantial spoken and written English-language difficulties. They opined that appropriate language-learning opportunity is essential $^{11}$.

\section{Conclusion}

To solve the problems with English used in Anatomy the weak areas may be defined very specifically by the personnel working in this field. On the basis of those common mistakes usually performed by the students, a short list may be prepared and provided to the students and teachers. A course on English language was present previously which was discontinued due to ineffectiveness and time constrain. There is a scope of course planners, English specialists and medical teachers to work together to find out practical approach to solve the existing problem pointed in this study.

\section{References}

1. Medical education in a multilingual and multicultural world (editorial). Medical Education 1993; 27: 3-5.

2. Ypinazar VA, Margolis SA. Western medical ethics taught to medical students can cross cultural and linguistic boundaries. BMC Medical Ethics 2004; 5(4): 1-13.

3. Hayes SC, Franill D, Sefton AJ. Improving English communication skills of preclinical medical students. Annals of Community Oriented Education 1994; 7: 317-327.

4. Hansen AC, Roberts JV. The evaluation of undergraduate students' written English language skills. Medical Education 2000; 34: 642-647.

5. Holbrook A, Bourke S. Assessment of the English skills of tertiary students. Higher Education Research and Development 1989; 8 (2): 161-179.

6. Cobbin D, Farrell H, Saunders S, Heyman S, Mohan T. Factors influencing undergraduate students' comprehension of technical texts. Sydney: Evaluative Studies Research Group, University of Technology; 1992.

7. Flaherty JA, Rezler A, Mcguire C. Clinical reading and writing skills of junior medical students. Medical Education 1982; 57(11): 848-853.

8. Yanoff KL, Burg FD. Types of medical writing and teaching of writing in U.S. medical schools. Medical Education 1998; 63: 30-7.

9. Letelier LM, Zamarin N, Andrade M, Gabrielli L, Caiozzi G, Viviani P, Riquelme A. Exploring Language Barriers to Evidence-based Health Care (EBHC) in Post-graduate Medical Students: A Randomised Trial. Education for Health 2007; 20 (3) : 1-6. Available from: http://www.educationforhealth.net/

10. Mirza DM, Hashim MJ. Communication Skills Training in English Alone Can Leave Arab Medical Students Unconfident with Patient Communication in their Native Language. Education for Health 2010; 23(2): 1-6.

Available from: http://www.educationforhealth.net/

11. Anna CH, Elizabeth ET, Charles KN, Adele HC. Assessment of English-language proficiency for general practitioner registrars. The Journal of Continuing Education in the Health Professions 2007; 27(1): $36-41$. 